\title{
Elintarviketuotannon ja elintarvikemarkkinoiden riippuvuus tuonnista
}

\author{
Marja Knuuttila ${ }^{1)}$, Eero Vatanen ${ }^{2)}$, Jyrki Niemi ${ }^{3)}$, Csaba Jansik ${ }^{3)}$ \\ ${ }^{1)}$ MTT taloustutkimus, Lönnrotinkatu 5, FI-50100 Mikkeli, etunimi.sukunimi@mtt.fi \\ ${ }^{2)}$ MTT taloustutkimus, C/。 Metsäntutkimuslaitos, PL 68,FI-80101 Joensuu, etunimi.sukunimi@mtt.fi \\ ${ }^{3)}$ MTT taloustutkimus, Latokartanonkaari 9, FI-00790 Helsinki, etunimi.sukunimi@mtt.fi
}

\section{Tiivistelmä}

Suomessa tuotetaan monia keskeisiä maatalousraaka-aineita - viljaa, lihaa, maitoa, munia, vihanneksia ja marjoja. Kun Suomessa sijaitseva elintarviketeollisuus jalostaa nämä raaka-aineet elintarvikkeiksi, on kyse ns. Suomessa tuotetusta eli kotimaisesta ruoasta. Elintarvikkeiden tuotantoketjuun sisältyvien tuontipanoksien huomioon ottaminen muuttaa elintarviketuotannon kotimaisuuden kotimaisuusasteeksi tai tuonnin näkökulmasta tuontiasteeksi. Elintarviketuotannon ja elintarvikemarkkinoiden tuontiasteesta ei ole ollut aiemmin käytettävissä yksiselitteistä tutkimustietoa.

Tutkimuksessa johdetaan elintarviketuotannon tuontipanosasteen ja elintarvikemarkkinoiden tuontiasteiden mittaustavat panos-tuotosmenetelmän avulla. Kotimaisen elintarviketuotannon tuontipanosasteen ja elintarvikemarkkinoiden tuontiasteen laskemisen tuloksia voidaan käyttää esimerkiksi huoltovarmuuden turvaamisen määrittelyyn. Myös normaalitilanteissa tuontiasteet ovat keskeisiä käsitteitä ja mittareita arvioitaessa elintarviketuonnin ja panostuonnin korvattavuutta kotimaisilla tuotteilla.

Elintarvikeketjun toimialojen tuontipanosasteen selvittämisessä tutkimusmenetelmänä käytetään panos-tuotosmenetelmän tuotosmallia, jonka avulla selvitetään toimialojen tuotoksien olemassa olevilla riippuvuussuhteilla elintarviketuotannon alojen välilliset tuontipanosten määrät vuosina 2003-2008. Hankkeen toteutuksessa hyödynnetään Tilastokeskuksen (TK) koko maan panos-tuotosaineistoja, Tullin ulkomaankauppatilastoja sekä aiemmin tehtyjä selvityksiä elintarvikesektorin huoltovarmuudesta. Käytetyssä koko maan panos-tuotosaineistossa maataloutta analysoidaan neljän ja elintarviketeollisuutta yhdeksän toimialan tarkkuudella.

Kun tarkasteluun otetaan huomioon myös valmiiden elintarvikkeiden tuonti, voidaan määrittää, mikä on elintarvikemarkkinoiden kokonaistuontiaste. Tulokset voidaan esittää vuosittain. Artikkelissa esitellään alustavia tuloksia vuosilta 2003-2007.

Elintarvikealojen tuontipanosaste vaihteli Kasvi- ja eläinrasvojen jalostuksen noin 47 prosentista Maatalouden 12 prosenttiin vuonna 2007. Alkutuotannon ja palvelualojen tuontipanosasteet Muuta kotieläintaloutta lukuun ottamatta olivat alle kaikkien toimialojen tuontipanosasteen keskiarvon $(24,6 \%)$ sen sijaan elintarvikejalostuksen toimialat ylittivät keskiarvon Lihanjalostusta ja Meijerituotteita lukuun ottamatta. Elintarvikealojen tuontipanosasteiden nousua selitti pääsääntöisesti se, että niiden tuonnin arvot kasvoivat enemmän kuin tuotoksen arvot.

Asiasanat: elintarvikeala, tuontipanos, tuotosmalli 


\section{Johdanto}

Tuotannossa käytetään kotimaisia ja ulkomaisia tuotantopanoksia. Osa panoksista tuodaan siksi, ettei kotimaista tarjontaa ole riittävästi tai lainkaan. Myös kotimaisten ja tuontipanosten hintasuhteet, laatu ja toimitusvarmuudet vaikuttavat yritysten tuontipäätöksiin. Tässä tutkimushankkeessa selvitetään panostuonnin osuutta elintarvikeketjun toimialojen tuotannossa.

Kun kotimainen elintarviketeollisuus jalostaa Suomessa tuotetuista maatalousraaka-aineista elintarvikkeita, puhutaan kotimaisesta elintarviketuotannosta ja kotimaisista elintarvikkeista. Tuontipanosten huomioon ottaminen muuttaa elintarvikkeiden kotimaisuuden kotimaisuusasteeksi tai tuonnin näkökulmasta tuontiasteeksi.

Elintarvikealojen panostuonnin lisäksi hankkeessa selvitetään valmiselintarvikkeiden tuontia kaupan hyllylle. Kun otetaan huomioon sekä elintarvikealojen tuotantoon sisältyvä panostuonti että valmiselintarviketuonti, niin voidaan puhua elintarvikemarkkinoihin liittyvästä kokonaistuonnista.

Tutkimus tuo lisätietoa elintarvikkeiden kotimaisuudesta tuotantopanosten käytön näkökulmasta. Rajauksena on, että tässä tutkimuksessa pääpaino on sellaisissa tavaroissa ja palveluissa, joiden käyttö tuotannossa on kertaluonteista. Pitkäkestoisten tuotantopanosten eli investointihyödykkeiden tuontia hankkeessa tarkastellaan vain suuntaa antavasti.

Koska tuontipanosyksiköt voidaan yhteismitallistaa vain arvomääräisinä, elintarviketuotannon alojen tuontipanosaste selvitetään tuontipanosten arvon osuutena tuotoksen arvosta. Elintarvikealan oman valmistuksen ulkomaiset panokset ovat välitöntä tuontia ja hankittujen kotimaisten panosten valmistukseen sisältyvät ulkomaiset panokset ovat välillistä tuontia. Tutkimuksen pääasiallinen aineisto on Tilastokeskuksen (TK) tuottama kansantalouden tilinpidon panos-tuotosaineisto, joka kuvaa toimialojen tuotannon panoskäytön. Menetelmänä käytetään panos-tuotosmenetelmän tuotosmallia, jonka avulla voidaan selvittää toimialan tuotannon vaatima välillinen panoskäyttö tuontipanoksineen.

Kansantalouden tilinpidossa tuotannon arvoa kutsutaan tuotokseksi ja kertaluonteisten panosten käyttöä välituotekäytöksi. Yleiskielessä tuotokseen viitataan usein tuotannon bruttoarvolla ja liikevaihdolla. Tuotos kuvaa niiden tulojen suuruuden, jotka tuotantotoiminnan harjoittamisessa on saatu. Tulot käytetään tuotantotoiminnassa panosten ja tuotannontekijöiden hankintaan.

Tutkittavia elintarvikealoja on yhteensä kuusitoista. TK:n tarkennetussa panos-tuotosaineistossa maataloudessa on neljä ja elintarviketeollisuudessa yhdeksän toimialaa. Esimerkkinä palvelualan tuotannon ja tuonnin rakenteesta elintarvikeketjussa tarkastellaan ravitsemispalveluja. Elintarvikekauppaa tarkastellaan ainoastaan osana kaupan toimialoista, sillä elintarvikkeiden kaupasta ja tuotannon rakenteesta ei ole saatavilla riittävää informaatiota.

\section{Aineisto ja menetelmät}

\section{Tuotosmalli toimialojen panostuonnin laskentavälineenä}

Elintarviketoimialojen panostuonnin laskentamenetelmänä käytetään tuotosmallia (ks. Knuuttila ym. 2007, Vatanen 2011), joka johdetaan perinteisestä panos-tuotosmallista (Leontiefin malli).

$$
\mathbf{X}=(\mathbf{I}-\mathbf{A})^{-1} \mathbf{Y}
$$

missä

$$
\begin{aligned}
& \mathbf{X}=\text { toimialojen tuotoksien (tulojen) vektori, } \\
& \mathbf{Y}=\text { toimialojen lopputuotekysyntöjen vektori ja }
\end{aligned}
$$

$(\mathbf{I}-\mathbf{A})^{-1}=$ toimialojen keskinäisiä riippuvuuksia kuvaava kerrannaismatriisi, ns. Leontiefin käänteismatriisi, jossa $\mathbf{I}$ on yksikkömatriisi ja $\mathbf{A}$ on panoskerroinmatriisi $\left(\mathbf{A}_{\mathrm{ij}}=\mathbf{Z}_{\mathrm{ij}} / \mathbf{X}_{\mathbf{j}}\right)$, jossa $\mathbf{Z}_{\mathrm{ij}}$ on toimialan $\mathbf{X}_{\mathbf{i}}$ tuotoksen käyttö toimialan $\mathbf{X}_{\mathbf{j}}$ välituotepanoksena.

Leontiefin mallissa toimialojen tuotokset ovat riippuvaisia kaikkien toimialojen lopputuotekysynnöistä ja tarkasteltavan talouden toimialojen keskinäisistä riippuvuuksista (panoskäytöstä). Tuotosmallissa selittäviä muuttujia ovat lopputuotekysyntöjen asemasta kaikkien toimialojen tuotokset 
(ks. Vatanen 2011). Tuotosmallin kerrannaismatriisi on Leontiefin mallin käänteismatriisin muunnos. Formaalisti muunnos suoritetaan jakamalla Leontiefin matriisin kunkin sarakkeen luvut saman sarakkeen diagonaaliluvulla eli matriisilaskentaa käyttäen

$\mathbf{T F}=(\mathbf{I}-\mathbf{A})^{-1} \hat{\mathbf{D}}^{-.1}$,

missä $\hat{\mathbf{D}}^{-1}$ on Leontiefin käänteismatriisin $(\mathbf{I}-\mathbf{A})^{-1}$ diagonaalivektorista muodostetun diagonaalimatriisin käänteismatriisi.

Analyyseissä TF-matriisia käytetään kuten Leontiefin käänteismatriisia (ks. Vatanen 2011, 22 23). TF-matriisin sarakesummat eli tuotantokertoimet osoittavat, miten sarakkeen toimialan tuotosyksikön valmistaminen edellyttää tuotantoa talouden eri toimialoilla yhteensä. Tuotantokertoimien vertailu osoittaa, millaiset ovat kunkin toimialan tuotosyksikön valmistamisen aiheuttamat kokonaisvaikutukset suhteessa toisiinsa.

Tuotostarkastelussa on ensisijaisesti kyse ex post -tarkastelusta eli siinä kuvataan niitä vaikutuksia, jotka liittyvät tarkasteltavan toimialan tuotokseen tiettynä ajankohtana (Szyrmer 1992). Täten tuotosmalli soveltuu parhaiten olemassa olevan ja havainnoidun tuotoksen rakenteiden ja vuorovaikutussuhteiden selittämiseen.

Tuotosmallin avulla voidaan määrittää toimialan tuotoksen bruttovaikutukset (euroina) taloudessa, kun tarkastellaan tuotosyksikön sijasta koko tuotosta. Toimialan tuotoksen muille toimialoille aiheuttama tuotosvaikutus saadaan kertomalla TF-matriisilla tuotoksista muodostettu diagonaalimatriisi $\hat{\mathbf{X}}$ :

$\mathbf{R}=(\mathbf{T F}) \hat{\mathbf{X}}$,

missä $\mathbf{R}$ on tuotosvaikutusmatriisi eli tuotoksen analyysimatriisi, jonka diagonaalisoluissa ovat toimialojen tuotokset, ja sarakkeen ei-diagonaalisolut osoittavat, miten sarakkeen toimialan tuotos on edellyttänyt tuotosta rivien toimialoilta. Sarakesumma on toimialan bruttovaikutus taloudessa. Toisin sanoen se kuvaa sitä vaikutusta, mikä taloudessa menetettäisiin, jos toimiala yhtäkkiä häviäisi taloudesta. (Vatanen 2001, Cai \& Leung 2004)

\section{Tuotoksen tuontivaikutusten laskenta}

Toimialan tuotantoprosessissaan käyttämien tuontihyödykkeiden arvo suhteessa toimialan tuotoksen arvoon on toimialan välitön tuontiaste. Tuontiasteen $m_{j}$ laskutapa määritellään yhden toimialan tapauksena yhtälössä (4) ja kaikkien toimialojen tuontiasteet m matriisiyhtälössä (5).

$m_{j}=\frac{M_{j}}{X_{j}}$

jossa $X_{j}$ ja $M_{j}$ ovat toimialan i tuotos ja välitön tuonti.

$\mathbf{m}^{\prime}=\mathbf{M}^{\prime} \hat{\mathbf{X}}^{-1}$

jossa $\hat{\mathbf{X}}^{-1}$ on kaikkien toimialojen tuotoksien diagonaali-

matriisin käänteismatriisi ja M' kaikkien toimialojen

tuonnit sisältämä vaakavektori.

Välittömän tuonnin lisäksi toimialojen tuotokseen sisältyy välillistä tuontia, joka on kunkin toimialan muilta toimialoilta ostamien kotimaisten panosten valmistuksessa käytettyä välitöntä tuontia. Tuotosmallin logiikan perusteella toimialojen $\mathrm{i}$ välitön tuonti on riippuvaista toimialan $\mathrm{j}: \mathrm{n}$ tuotoksesta siltä osin kuin se edellyttää toimialojen i tuotosta panoksenaan. Toimialan $j$ tuotoksen edellyttämä kokonaistuontipanosaste on täten (välitön tuonti + välillinen tuonti)/ tuotos. Kokonaistuontipanosasteen kaavat yhden ja kaikkien toimialojen tapauksena esitetään yhtälöissä (6) ja (7).

$m t_{j}=\frac{M_{j}+I M_{j}}{X_{j}}$

jossa $X_{j}, M_{j}$ ja $I M_{j}$ ovat toimialan j tuotos, välitön ja

välillinen tuonti. 
$\mathbf{m t} \mathbf{t}^{\prime}=\mathbf{M}^{\prime} \mathbf{R} \hat{\mathbf{X}}^{-1}$

jossa $\mathbf{m t}$ ' on kaikkien toimialojen tuotoksen

kokonaistuontipanosasteet $m t_{j}$ esittävä vektori.

Toimialojen tuotoksen edellyttämät eri tuontituotteiden kokonaismäärät (arvot) voidaan laskea, kun tiedetään eri toimialojen tuonnit hyödykkeittäin. Tätä varten määritetään, kunkin toimialan välitön tuontiaste hyödykkeittäin, joka on

$\mathbf{m c}=\mathbf{M C \hat { \mathbf { X } } ^ { - 1 }}$

jossa MC on eri hyödykkeiden välitöntä tuontia toimialoittain kuvaava

matriisi ja mc on toimialojen eri tuotteiden välittömät tuontipanosasteet

Kunkin toimialan $\mathrm{j}$ edellyttämä eri tuontituotteiden kokonaismäärä voidaan laskea tulosmatriisi $\mathbf{R M C}^{\mathrm{j}}$ :n avulla, joka saadaan, kun me matriisilla kerrotaan tuotosanalyysimatriisin $\mathbf{R}$ sarakkeesta $\mathbf{j}$ muodostettu diagonaalimatriisi (yhtälö 9). Tulosmatriisi $\mathbf{R M C} \mathbf{C}^{\mathrm{j}}$ :n sarakkeelta nähdään kuinka paljon toimiala j:n tuotoksen edellyttämä tuotos eri toimialoilta edellyttää eri tuotteiden tuontia = tulosmatriisin RMC:n sarakkeiden solut. Tulosmatriisin rivisummat $\mathrm{MC}_{\mathrm{i}}{ }^{\mathrm{j}}$ eli summat sarakkeiden yli osoittavat, kuinka paljon kutakin tuotetta on pitänyt tuoda toimiala j: tuotoksen valmistamista varten (yhtälö 10). Toimialan j:n tuotoksen edellyttämä eri hyödykkeiden kokonaistuonti on sen kaikkien tuotujen hyödykkeiden summa (yhtälö 11), joka on sama kuin toimialan välitön ja välillinen tuonti yhteensä yhtälössä 6 .

$$
\begin{aligned}
& \mathbf{R M C}^{j}=\mathbf{m c}_{\mathbf{j}} \\
& \mathbf{M C}_{i}^{j}=\mathbf{R M C}^{j} \mathbf{i} \\
& M C^{j}=\mathbf{i}^{\prime} \mathbf{M C} C_{i}^{j} \\
& M C^{j}=M_{j}+I M_{j} .
\end{aligned}
$$

\begin{abstract}
Aineisto
Tutkimusaineistona käytetään TK:sta tilattuja kansantalouden tilinpidon tarkennettuja koko maan panos-tuotostauluja vuosilta 2003-2007 (vuosi 2008 valmistuu joulukuussa 2011). Useamman vuoden aineisto mahdollistaa luotettavamman kuvan saamisen elintarvikealojen tuotannon tuontipanosasteesta. Aineiston hintakäsite on perushinta. Maatalouden perushintaiseen tuotokseen olemme lisänneet maatalouden muut tuotantotukipalkkiot.
\end{abstract}

\title{
Tulokset
}

Elintarvikealojen tuontipanosaste vaihtelee Kasvi- ja eläinrasvojen jalostuksen noin 47 prosentista Maatalouden noin 12 prosenttiin (kuvio 1). Tuontipanosmäärät ovat näissä kahdessa kuitenkin eri luokkaa (Kasvi- ja eläinrasvat 82 milj. $€$ ja Maatalous 669 milj. $€$ vuonna 2007) (kuvio 2). Yli 30 prosentin tuontipanosaste on lisäksi Eläinten ruoissa ja Kalanjalostuksessa. Elintarvikejalostuksessa ja palvelualoilla tuontipanosaste on Maataloutta korkeampi.

Kasvi- ja eläinrasvojen ja Eläinten ruokien korkeat tuontipanosasteet ilmaisevat Suomen öljykasvi- ja valkuaiskasvivajeen aiheuttamia tuontitarpeita.

Alkutuotannon alojen tuontipanosasteet Muuta kotieläintaloutta lukuun ottamatta ovat alle kaikkien toimialojen (yht. $72 \mathrm{kpl}$ ) tuontipanosasteen keskiarvon (24,6 \%). Elintarvikejalostuksen alat puolestaan ylittävät keskiarvon Lihanjalostusta ja Meijerituotteita lukuun ottamatta. Palvelualojen kauppa ja ravitseminen tuontipanosasteet ovat alle keskiarvon. 

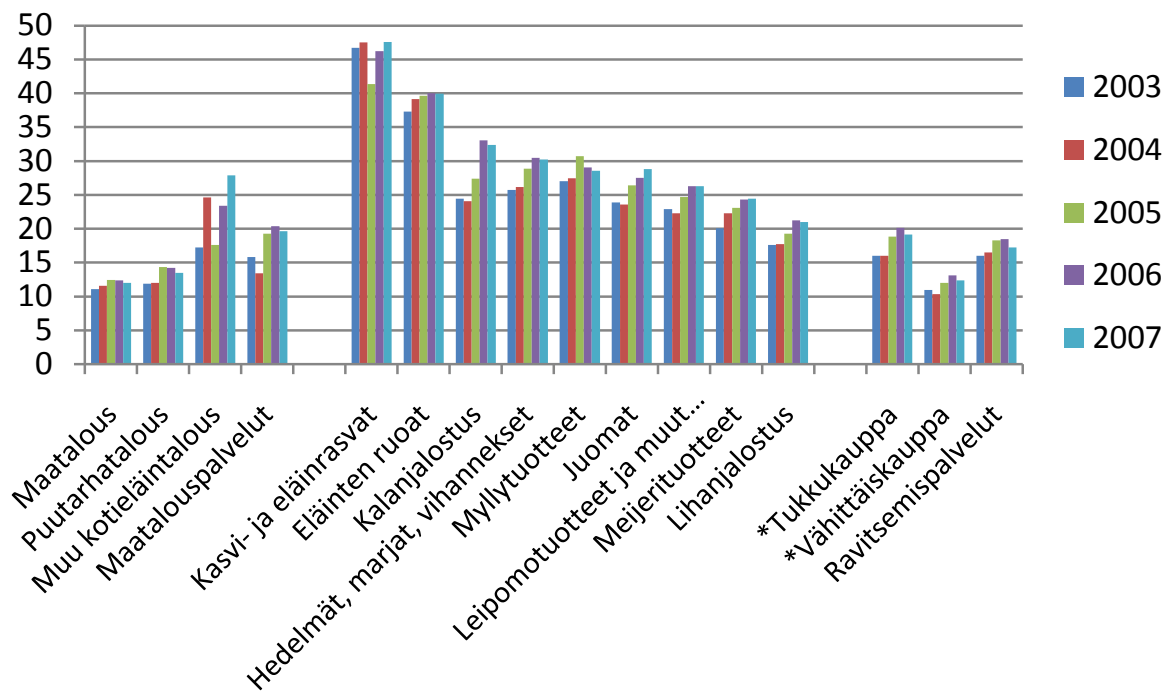

*) Kuvaa koko kaupan tuontiastetta, ei huomioi elintarvikekaupan erityispiirteitä.

Kuvio 1. Elintarvikealojen tuontipanosasteet vuosina 2003-2007, \%.
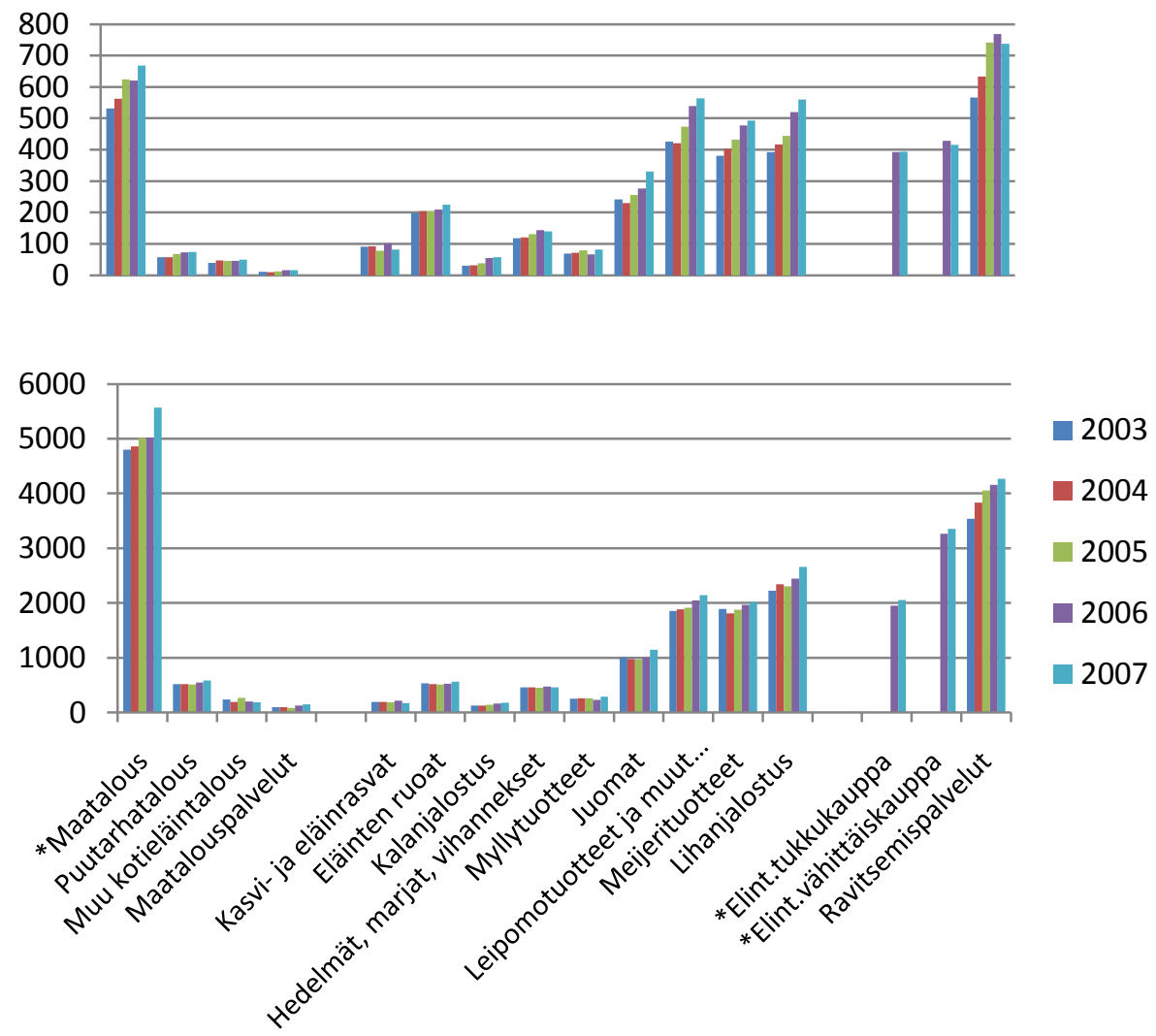

*) Maatalouden perushintaiseen tuotokseen on lisätty muut tuotantotukipalkkiot. Elintarvikkeiden tukkukaupan ja vähittäiskaupan tuotokset on arvioitu tutkimuksessa vuosille 2006-2007.

Kuvio 2. Elintarvikealojen tuotos (alhaalla) ja panostuonti (ylhäällä) vuosina 2003-2007, milj. € (käyvin hinnoin). (Lähde: Suomen virallinen tilasto SVT: Panos-tuotos, tarkennettu toimialajako. Tutkimuksen analyysit) 
Kaikkien elintarvikealojen tuontipanosasteet ovat nousseet. Suurin nousu on Muussa kotieläintaloudessa ja pienin Kasvi- ja eläinrasvojen jalostuksessa (kuvio 1). Panos-tuotosaineistosta ei voida johtaa, mikä osa noususta on seurausta tuontimäärien ja mikä tuontihintojen vaihteluista. Sen sijaan voidaan arvioida, miten tuontipanosasteeseen vaikuttavat tuonnin ja tuotoksen arvojen muutokset.

Miltei kaikkien elintarvikealojen tuotoksen ja tuonnin arvo on kasvanut vuodesta 2003 vuoteen 2007 (kuvio 2). Tuontipanosasteen nousut selittää pääsääntöisesti se, että tuonnin arvo on noussut enemmän kuin tuotoksen arvo (kokonaisdifferentiaalitarkastelu). Vain Muun kotieläintalouden ja Kasvi- ja eläinrasvojen aloilla tuotoksen arvon lasku on vaikuttanut positiivisesti tuontipanosasteen nousuun ja jälkimmäisellä alalla tuontipanosasteen muutos on tuonnin arvon samanaikaisen laskun vuoksi vähäinen.

Tuontipanosasteen vuosimuutosten suurimmat vaihtelut ovat pienillä aloilla Muussa kotieläintaloudessa, Maatalouspalveluissa ja Kalanjalostuksessa. Suuremmilla toimialoilla vuosivaihtelu on vähäistä trendimuutoksen ympärillä.

Eri alat tuovat samanlaisia ja erilaisia hyödykkeitä. Muut liike-elämän palvelut ja Kemikaalit, kemialliset tuotteet ovat viiden suurimman tuotteen joukossa suurimmilla aloilla. Maataloudessa kemikaalien osuus kokonaispanostuonnista on $23 \%$. (taulukko 1.) Aineiston perusteella ei voi sanoa tarkemmin, mitä tuotteita esimerkiksi Maatalouden tai Lihanjalostuksen kemikaalit ovat. Maataloudessa käytettävät lannoitteet, torjunta-, säilöntä- ja puhdistusaineet selittänevät suurelta osin tämän tuonnin. Välillisenä tuontina ne näkyvät myös Lihanjalostuksessa, Meijeriteollisuudessa ja Ravitsemispalveluissa. Sen sijaan Muiden liike-elämän palvelujen tuonti vaatii lisäselvittelyä.

Suurin välittömän panostuonnin osuus on Kasvi- ja eläinrasvojen valmistuksessa 76 prosenttia ja pienin Muussa kotieläintaloudessa 19 prosenttia (taulukko 2). Välittömän ja välillisen panostuonnin osuuksiin vaikuttavat elintarvikealan tuotannon rakenne ja tuotantoketjun pituus.

Taulukko 1. Suurimpien elintarvikealojen (Maatalous, Lihanjalostus, Meijerituotteet, Ravitsemispalvelut) kokonaispanostuonti ja viisi tärkeintä tuontituotetta vuonna 2007, milj. $€$.

\begin{tabular}{|c|c|c|c|}
\hline Maatalous & Lihanjalostus & Meijeriteollisuus & Ravitsemispalvelut \\
\hline 1. Kemikaalit, kemialliset tuotteet & 1. Muut liike-elämän palvelut & 1. Kemikaalit, kemialliset tuotteet ja & 1. Muut liike-elämän palvelut \\
\hline ja tekokuidut (157 milj. €) & $(80 \mathrm{milj} . €)$ & tekokuidut (91 milj. €) & (91 milj. €) \\
\hline $\begin{array}{l}\text { 2. Raakaöljy ja luonnonkaasu } \\
\text { (77 milj. €) }\end{array}$ & $\begin{array}{l}\text { 2. Kemikaalit, kemialliset tuotteet } \\
\text { ja tekokuidut ( } 67 \text { milj. } €)\end{array}$ & $\begin{array}{l}\text { 2. Munt liike-elämän palvelut } \\
\text { (54 milj. } €)\end{array}$ & $\begin{array}{l}\text { 2. Мии elintarvikkeiden valmistus } \\
\text { (89 milj. } €)\end{array}$ \\
\hline 3. Koksi, öljytuotteet ja ydinpolttoai- & 3. Teurastus, lihanjalostus ja lihan & 3. Raakä̈ljy ja luonnonkaasu & 3. Puutarhatalous (60 milj. €) \\
\hline ne (59 milj. €) & sailyvyyskasittely $(\mathrm{b} / \mathrm{mil \textrm {j }} . \mathrm{E}$ & $X \quad \cdot \cdots$ & Kemikaalit, kemialliset tuotteet \\
\hline $\begin{array}{l}\text { 4. Kasvi- ja eläinöljyjen ja -rasvojen } \\
\text { valmistus ( } 50 \text { milj. } €)\end{array}$ & $\begin{array}{l}\text { 4. Raakaöljy ja luonnonkaasu } \\
\text { (39 milj. €) }\end{array}$ & $\begin{array}{l}\text { 4. Koksi, öljytuotteet ja ydinpoltto- } \\
\text { aine ( } 32 \text { milj. } €)\end{array}$ & $\begin{array}{l}\text { ja tekokuidut }(39 \text { milj. } €) \\
5 \text { Juomien valmistus }(38 \text { mili } €)\end{array}$ \\
\hline $\begin{array}{l}\text { 5. Muut liike-elämän palvelut } \\
(40 \text { milj. } €)\end{array}$ & $\begin{array}{l}\text { 5. Koksi, öljytuotteet ja ydinpoltto- } \\
\text { aine ( } 30 \text { milj. } €)\end{array}$ & $\begin{array}{l}\text { 5. Kumi-ja muovituotteet } \\
(29 \text { milj. } €)\end{array}$ & \\
\hline Yht. 669 milj. $€$ & Yht. 559 milj. $€$ & Yht. 493 milj. $€$ & Yht. 737 milj. € \\
\hline
\end{tabular}

Taulukko 2. Elintarvikealojen kokonaispanostuonnin jakaantuminen välittömään ja välilliseen vuonna 2007, \% (milj. €).

\begin{tabular}{|c|c|c|c|c|c|c|c|c|c|c|c|c|c|c|c|c|}
\hline & $\begin{array}{l}\text { Maa- } \\
\text { talous }\end{array}$ & $\begin{array}{l}\text { Puu- } \\
\text { tarha- } \\
\text { talous }\end{array}$ & $\begin{array}{l}\text { Muu } \\
\text { koti- } \\
\text { eläin- } \\
\text { talous }\end{array}$ & $\begin{array}{l}\text { Maa- } \\
\text { talous- } \\
\text { pal- } \\
\text { velut }\end{array}$ & $\begin{array}{l}\text { Kasvi- } \\
\text { ja } \\
\text { eläin- } \\
\text { rasvat }\end{array}$ & $\begin{array}{c}\text { Eläin- } \\
\text { ten } \\
\text { ruoat }\end{array}$ & $\begin{array}{c}\text { Kalan- } \\
\text { jalos- } \\
\text { tus }\end{array}$ & $\begin{array}{c}\text { Hedel- } \\
\text { mät } \\
\text { ym. }\end{array}$ & $\begin{array}{c}\text { Mylly- } \\
\text { tuot- } \\
\text { teet }\end{array}$ & $\begin{array}{l}\text { Juo- } \\
\text { mat }\end{array}$ & $\begin{array}{c}\text { Leipo- } \\
\text { motuot- } \\
\text { teet } \\
\text { ym. }\end{array}$ & $\begin{array}{l}\text { Meije- } \\
\text { ri-tuot- } \\
\text { teet }\end{array}$ & $\begin{array}{l}\text { Lihan- } \\
\text { jalos- } \\
\text { tus }\end{array}$ & $\begin{array}{l}\text { Elint. } \\
\text { tukku- } \\
\text { kaup- } \\
\text { pa }^{*}\end{array}$ & $\begin{array}{c}\text { Elint. } \\
\text { vähit- } \\
\text { täis- } \\
\text { kauppa* }\end{array}$ & $\begin{array}{l}\text { Ravit- } \\
\text { semis- } \\
\text { palve- } \\
\text { lut }\end{array}$ \\
\hline Välitön & 32 & 41 & 19 & 27 & 76 & 42 & 61 & 67 & 67 & 39 & 71 & 53 & 44 & 63 & 50 & 45 \\
\hline Välillinen & 68 & 59 & 81 & 73 & 24 & 58 & 39 & 33 & 33 & 61 & 29 & 47 & 56 & 37 & 50 & 55 \\
\hline $\begin{array}{r}\% \\
\text { (milj. } €)\end{array}$ & $\begin{array}{c}100 \\
(669)\end{array}$ & $\begin{array}{l}100 \\
(74)\end{array}$ & $\begin{array}{l}100 \\
(51)\end{array}$ & $\begin{array}{l}100 \\
(16)\end{array}$ & $\begin{array}{l}100 \\
(82)\end{array}$ & $\begin{array}{c}100 \\
(224)\end{array}$ & $\begin{array}{l}100 \\
(58)\end{array}$ & $\begin{array}{c}100 \\
(139)\end{array}$ & $\begin{array}{l}100 \\
(82)\end{array}$ & $\begin{array}{c}100 \\
(331)\end{array}$ & $\begin{array}{c}100 \\
(564)\end{array}$ & $\begin{array}{c}100 \\
(493)\end{array}$ & $\begin{array}{c}100 \\
(559)\end{array}$ & $\begin{array}{c}100 \\
(394)\end{array}$ & $\begin{array}{c}100 \\
(415)\end{array}$ & $\begin{array}{l}100 \\
(737)\end{array}$ \\
\hline
\end{tabular}

*) Elintarvikekaupan panostuonnin osuus koko kaupan panostuonnista arvioitu. 


\section{Elintarvikemarkkinoiden riippuvuus tuonnista}

Elintarvikemarkkinoiden kokonaistuonti
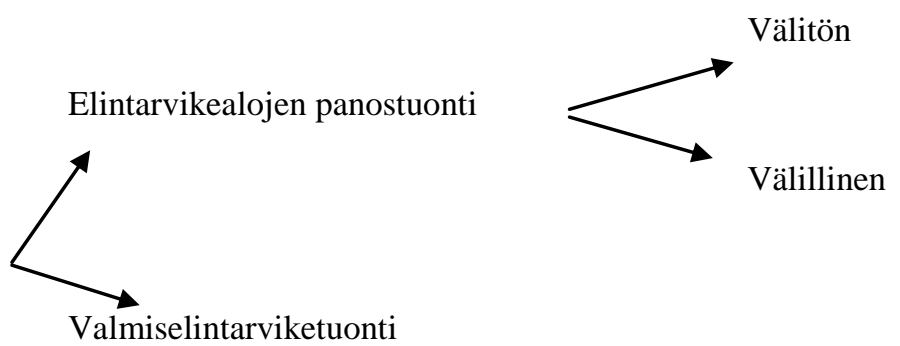

Kuvio 3. Elintarvikemarkkinoiden kokonaistuonti.

Kun elintarvikealojen panostuontiin (välitön ja välillinen) lisätään valmiiden elintarvikkeiden tuonti, saadaan elintarvikemarkkinoiden kokonaistuonti (kuvio 3).

\section{Yhteenveto}

Artikkelissa esiteltiin menetelmiä ja alustavia tuloksia elintarvikealojen tuontipanosasteista ja elintarvikemarkkinoiden tuontiasteen laskemisesta.

Elintarvikealojen tuontipanosaste vaihteli Kasvi- ja eläinrasvojen jalostuksen noin 47 prosentista Maatalouden 12 prosenttiin. Alkutuotannon ja palvelualojen tuontipanosasteet Muuta kotieläintaloutta lukuun ottamatta olivat alle kaikkien toimialojen tuontipanosasteen keskiarvon $(24,6 \%)$ sen sijaan elintarvikejalostuksen toimialat ylittivät keskiarvon Lihanjalostusta ja Meijerituotteita lukuun ottamatta. Elintarvikealojen tuontipanosasteiden nousua selitti pääsääntöisesti se, että niiden tuonnin arvot kasvoivat enemmän kuin tuotoksen arvot.

Elintarvikealojen tuontipanosasteesta ei ole aikaisempia tutkimustuloksia, joten vertailutietoa tulosten arvioinnille ei ole käytettävissä. Tutkimuksen tuloksia ja niiden luotettavuutta arvioidaan yhdessä elintarvikealojen asiantuntijoiden kanssa.

\section{Kirjallisuus}

Cai, J. \& Leung, P. 2004. Linkage Measures: a Revisit and Suggested Alternative. Economic Systems Research, 16, 65-85.

Knuuttila, M., Vatanen, E. \& Jansik, C. 2007. Finnish food industry in 1989-2002: an output-oriented inputoutput analysis. Acta Agriculturae Scandinavica, Section C: Food Economics 4(4): 217-228.

Suomen virallinen tilasto (SVT): Panos-tuotos [verkkojulkaisu]. ISSN=1799-1994. Helsinki: Tilastokeskus [viitattu: 25.11.2011]. Saantitapa: http://www.stat.fi/til/pt/index.html. (tarkennettu toimialajako)

Szyrmer, J. 1992. "Input-output coefficients and multipliers from a total-flow perspective". Environment and Planning A, 1992, 921-937.

Vatanen, E. 2001. Puunkorjuun ja puunkuljetuksen paikallistaloudelliset vaikutukset Juvan, Keuruun ja Pielisen Karjalan seutukunnissa. Metsäntutkimuslaitoksen tiedonantoja 825, 2001. Joensuun tutkimuskeskus.

Vatanen, E. 2011. Tuotosmalli panos-tuotosanalyysin välineenä - menetelmä, teoria ja paikallistaloudelliset sovellukset. Publications of the University of Eastern Finland. Dissertations in Social Sciences and Business Studies. N:o 19. 